\title{
Growth response of Mediterranean herbaceous swards to inoculation with Azospirillum brasilense
}

\author{
E. ZAADY, Y. OKON, AND A. PEREVOLOTSKY
}

\begin{abstract}
Authors are with the Hebrew Univ. of Jerusalem, Faculty of Agriculture, Dep. of Plant Pathology and Microbiology, Rehovot 76100, Israel; Dep. of Natural Resources, ARO, The Volcani Center, P.O. Box 6, Bet Dagan 50250, Israel.
\end{abstract}

\begin{abstract}
A study was conducted on the effect of the rhizobacterium A zospirillum brasilense strain Cd on the production of herbaceous swards growing at 2 rangeland habitats in Israel. One habitat was the semiarid zone $(<\mathbf{3 0 0} \mathrm{mm}$ annual rainfall, calcareous soil on rocky slopes) while the other was a typical Mediterranean zone ( $\sim 600 \mathrm{~mm}$ annual rainfall, karstic rock covered with terra rossa soil). The inoculum was applied in water suspension at a concentration of $10^{8}$ colony forming units (CFU) $\mathrm{ml}^{-1}$. The effect of inoculation was compared with $P$-fertilizer application at a rate of $5 \mathrm{~g} / \mathrm{m}^{2}$. The same treatments were also applied on potted soil from the 2 sites. The semiarid ecosystem showed a strong response to Azospirillum inoculation, to P-fertilizer and to the combination of these 2 treatments, with aerial biomass production increasing by approximately fourfold in the treatments as compared with the control. The response to inoculation or P-fertilization was similar, with no interaction or additive effect noted for the combined treatment. At the Mediterranean site, the response to inoculation or P-fertilization alone was variable, with only a moderate effect on biomass production as compared with the control; however, the inoculation-fertilization interaction was highly significant and doubled biomass production. In the greenhouse experiment, the response to inoculation or fertilization was significant and the biomass production at the end of the growing season was approximately $50 \%$ higher than in the control. At both sites, standing biomass was greater in the treated plots already at early stages of growth, thereby potentially lengthening the effective grazing season. It is suggested that inoculation with $A$ zospirillum brasilense on a commercial scale may offer a means of increasing rangeland production without resorting to costly and ecologically unfavorable fertilizer application.
\end{abstract}

Key Words: Azospirillum, inoculation, rangeland improvement, fertilization

Enrichment of deficient soils with fertilizers is a well-known, if not commonly practiced, range improvement technique. However, its interaction with local conditions can give rise to economic and/or ecological problems (Wight and Black 1979). This has prompted the search for alternative means capable of increasing range production without generating negative consequences.

Nitrogen-fixing bacteria of the genus Azospirillum have been suggested as an alternative or supplement to chemical fertilization (Baldani et al. 1983, Hegazi et al. 1983, Kapulnik et al. 1981, Mertens and Hess 1984, Reynders and Vlassak 1982). The plant growth-promoting effects of $A$. brasilense inoculation have been studied mainly with crop plants in field and pot experiments,

The authors wish to thank the Foundation for Ecology of the Jewish National Fund, the Range Management Advisory Board, and Pioneer France-Mais, Aussone, France for providing support for this work. We are grateful to Rafi Yonatan for the field assistance and to No'am Seligman for valuable comments on an earlier version of the manuscript.

Manuscript accepted $4 \mathrm{Jul} .1993$ usually in combination with different levels of $N, P$, and $K$ fertilization (Sarig et al. 1988, Sumner 1990). The possible effects of inoculation with Azospirillum on plant growth can be explained by its effect on root development. Inoculation has been shown to increase the total root surface under laboratory conditions (Fallik et al. 1988, Sumner 1990), thereby increasing potential mineral and water uptake by the plants (Lin et al. 1983, Sarig et al. 1988). In addition, Azospirillum has been shown to increase nitrogen fixation in the rhizosphere, thus enhancing the overall environment conducive to plant growth. In many cases, Azospirillum inoculation promoted growth and crop yield of agronomically important forage, grain grasses, and legumes (Okon 1985, Umali-Garcia et al. 1980, Sumner 1990). The bacteria may also affect plant growth by increasing nitrogen uptake in low-nitrogen soils and, more importantly, by producing plant growth substances such as indole-3acetic acid (IAA) (Barbieri et al. 1986, Fallik et al. 1989). In many field experiments it has been demonstrated that Azospirillum inoculants do not cause either environmental hazard (Fages, 1992) or any health problems in the plants (Okon et al. 1987).

The work reported here represents one of the first attempts to evaluate the effect of Azospirillum inoculation on the productivity of natural range vegetation. The response of natural pasture growing in 2 different habitats in Israel - semiarid (northern Negev) and Mediterranean climate (Mt. Carmel)-to inoculation with Azospirillum brasilense was compared with the effect of phosphatic fertilizer. The potential of using bacteria inoculation as a technique of range improvement is discussed.

\section{Materials and Methods}

Bacterial strain Azospirillum brasilense Cd (ATCC 29729), isolated from the roots of Cynodon dactylon, was used in all experiments.

\section{Experimental Sites}

The Lehavim site (LV) is located $15 \mathrm{~km}$ north of Be'er Sheva (latitude $31^{\circ} 22^{\prime} \mathrm{N}$, longitude $34^{\circ} 50^{\prime} \mathrm{E}$, elevation $400-450 \mathrm{~m}$ above sea level) in a semiarid region. The site receives $275 \mathrm{~mm}$ average annual precipitation and is covered by Rendzina soil (Rendoll) rich in loess. This soil, like most soils in the Negev, is considered deficient in all major minerals (Noy-Meir and Harpaz 1978).

The Ramat Hanadiv (RH) site is located at the southern tip of Mt. Carmel (latitude $32^{\circ} 35^{\prime} \mathrm{N}$, longitude $35^{\circ} 00^{\prime} \mathrm{E}$, elevation 120 $\mathrm{m})$ in a typically Mediterranean climate. The area receives 550-600 $\mathrm{mm}$ average annual rainfall and the rock-soil complex is composed mainly of hard limestone and P-deficient terra rossa (Kaplan 1989).

Preliminary observations showed relatively low available phosphate content at the experimental sites-an average of 6 and $13 \mathrm{mg}$ 
$\mathrm{P} / \mathrm{kg}$ soil at Ramat Hanadiv and I ehavim, respectively.

The vegetation of both regions is characterized by shrubs: dominant species in the Mediterranean region are Sarcopoterium spinossum (L.) Spach, Pistacia lentiscus, and Calycotome villosa (Poiret) Link. In the semiarid region, Sarcopotrium spinosum (L.) spach and Coridothymus capitatus $(\mathrm{L}$.) Reichb are predominant. These shrubs are generally unpalatable to most livestock. The open soil between shrubs is populated hy a very diverse community of herbaceous vegetation that develops after the first rainfall (January-February) and withers at the end of spring (end of April-May). It is the latter vegetation that is most important as forage for livestock, and the experiments were conducted in patches of this vegetation. The herbaceous community in Ramat Hanadiv was dominated by the species: Avena sterilis, Brachypodium distachyon, Synelcosciadium carmeli, and Anagallis arvensis. In Lehavim the most common species were: Aegilops sp., Rostraria cristata, Stipa capensis, Anthemis palestina and Paronychia argenta.

\section{Field Experiments}

Both sites were located in hilly areas. The experiments were initiated in the Mediterranean habitat (RH) in 1989 and continued throughout 1990 and 1991. At the semiarid site (LV), experiments ran for 2 years: 1990 and 1991. Each experiment consisted of 4 treatments:

1. Treatment A: was composed of inoculation with $A$. brasilense, at a concentration of $10^{8}$ colony forming units $(\mathrm{CFU}) / \mathrm{ml}$ in 2 liters of $34 \mathrm{mM}$ phosphate buffer ( $\mathrm{pH}$ 6.1) per plot $(4 \times 4 \mathrm{~m})$. The inoculum was applied in water suspension spread uniformly over the plots by a sprayer. Bacteria application followed the first heavy rains (approx. $10 \mathrm{~mm}$ rainfall), just before the next storm (usually in December). The amount of water added by the bacteria application was negligible (less than $1 \mathrm{~mm}$ ) as compared with the annual rainfall $(275 \mathrm{~mm})$.

2. Treatment $P$ : consisted of fertilization with $85 \%$ phosphoric acid (0-61-0), containing $61 \% \mathrm{P}_{2} \mathrm{O}_{5}$ (Haifa Chemicals, Israel), equivalent to $50 \mathrm{~kg} \mathrm{P} / \mathrm{ha}$ and applied after the first rains. The application technique was similar to that described for Treatment A.

3. Treatment A+P: Both inoculation and fertilization (i.e., combination of treatments 1 and 2)

4. Treatment C: Control-that received only 2 liters phospate buffer.

Each treatment was repeated on the same plot in years ( 3 in $\mathrm{RH}$ and 2 in LV).

\section{Preparation of Plots}

The experimental areas were cleared of perennial shrubs and 16- $\mathrm{m}^{2}$ plots were established. To prevent grazing (by wildlife at Ramat Hanadiv and sheep at Lehavim), the plots were fenced. Herbage yield was measured 4 to 5 times throughout the growing season (February-April) by harvesting all herbaceous vegetation in 5 quadrats $(25 \times 25 \mathrm{~cm}$ each) distributed randomly within the plot. Plant samples were dried at $80^{\circ} \mathrm{C}$ in an air-forced oven for 3 days and subsequently weighed.

\section{Greenhouse Experiments}

The same 4 treatments were also applied to plants growing in the greenhouse. Each treatment group consisted of 24 pots with $0.5 \mathrm{~kg}$ terra rossa soil from the Ramat Hanadiv site, from which plants and seeds had been removed. In each pot, $0.2 \mathrm{~g}$ of a seed mixture collected from the experimental sites was planted. The sown seeds (mainly Avena sterilis, Brachypodium distachyon, Synelcosciadium carmeli and Anagallis arvensis.) were inoculated with $5 \mathrm{ml}$ of $10^{8}\left(\mathrm{CFU} / \mathrm{ml}^{-1}\right.$ Azospirillum. The amount of $\mathrm{P}_{2} \mathrm{O}_{5}$ added was equivalent to $50 \mathrm{~kg} \mathrm{P} /$ ha. Irrigation was performed as necessary to maintain pot moisture throughout the entire growing period. Plants from 6 pots of each treatment were harvested and ovendried on 4 different dates.

\section{Statistical Analysis}

Field results were analyzed using the GLM procedure (Freund and Littell 1980). Significance at the $=0.05$ was considered indicative of true differences according to Duncan's Multiple Range Test.

\section{Results}

The effects of inoculation with Azospirillum on dry matter biomass yield in the semiarid ecosystem are presented in Figures 1 and 2. During the first growing season (January-April 1990), pasture production in the inoculated plots was statistically higher than that of the control at each sampling date (Fig. 1). At the peak

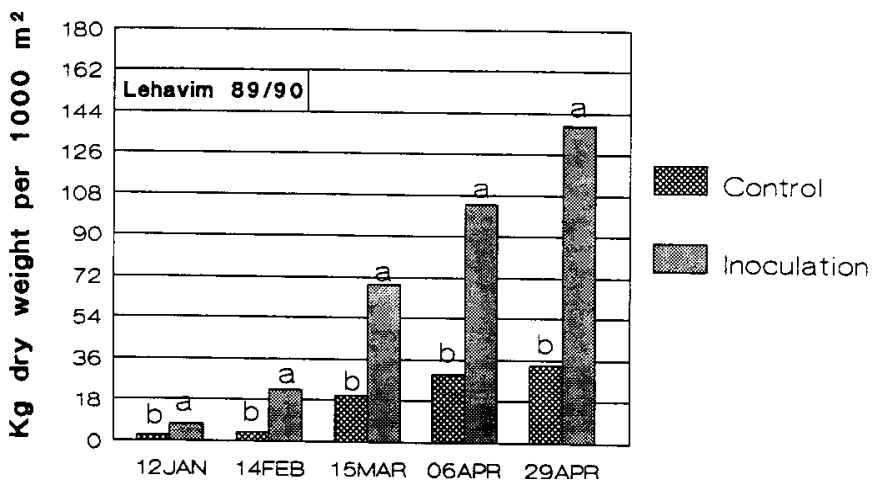

Harvest dates

Fig. 1. Effect of inoculation with A zospirillum brasilense Cd on the production of natural pasture in the northern Negev (Lehavim)-1989/90. Different letters at each sampling date indicate significant differences at $p<0.005$ in Duncan's Multiple Range Test.

of the growth season (end of April), 1,350 kg dry matter/ha were produced in the inoculated plots, as compared with $340 \mathrm{~kg}$ dry matter/ ha for the controls (i.e., an increase of about 350\%). Inoculation apparently influenced pasture productivity mainly during the latter part of the grazing season (mid-February-end of April). The rate of dry matter accumulation in the treated plots was 15 $\mathrm{kg} / \mathrm{ha} /$ day, as compared with $4.2 \mathrm{~kg} / \mathrm{ha} / \mathrm{d}$ for the control plots.

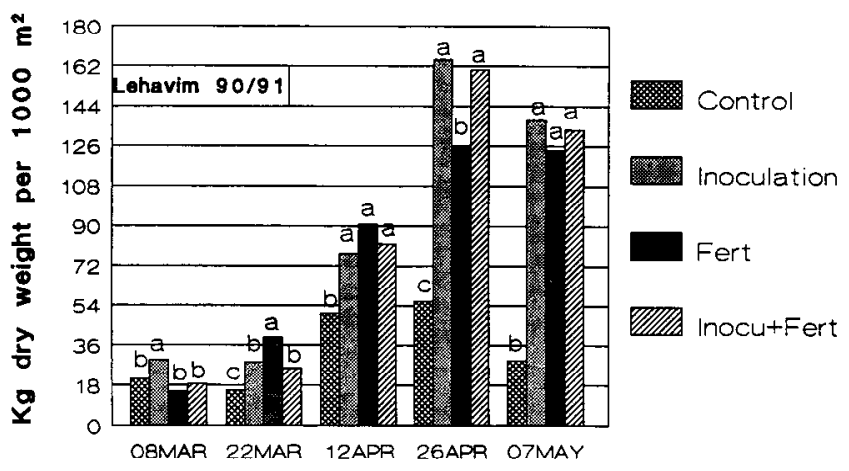

Harvest dates

Fig. 2. Effect of inoculation with Azospirillum brasilense Cd and phosphate fertilization on the production of natural pasture in the northern Negev (Lehavim) - 1990/91. 
During the second growing season (1991), phosphate fertilization was added to the experiment. Pasture production was significantly higher in all treatments as compared with the control (Fig. 2). At the peak of biomass production, the yields of the inoculated plots, the fertilized plots, and the plots that had undergone inoculation + fertilization were $1,650,1,200$, and $1,600 \mathrm{~kg}$ dry matter/ ha, respectively (Fig. 2), or $295 \%, 214 \%$, and $286 \%$ of the control yield ( $560 \mathrm{dry}$ matter/ha), respectively. Differences between treated and control plots showed up only at the second sampling (end of March). The rate of dry matter accumulation during the main growing season (beginning of March-end of April) was maintained at $29.5,23.0,28.3$, and $7.3 \mathrm{~kg}$ dry matter/ha/d for the combined (A+P) treatment, P-fertilization (P), Azospirillum inoculation (A) and the control $(\mathrm{C})$, respectively.

In the Mediterranean shrubby ecosystem (RH), pasture yields from the $\mathbf{4}$ treatments were not statistically different for the first season (1989). The maximum average yield obtained for this year was $850 \mathrm{~kg}$ dry matter/ha and the standard deviations were high.

In the second season $(1989 / 1990)$, throughout most of the growth period, the yield for all treatments improved significantly as compared with the control (Fig. 3). But at the end of the growing

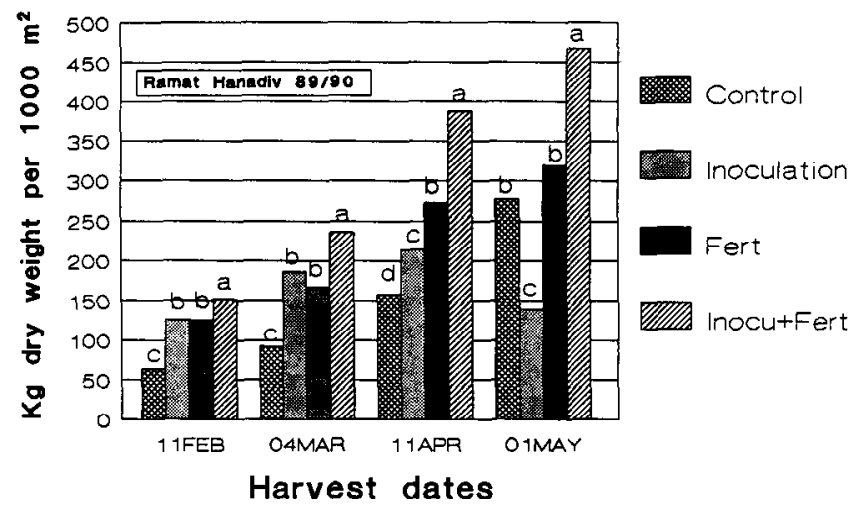

Fig. 3. Effect of inoculation with Azospirillum brasilense $\mathrm{Cd}$ and phosphate fertilization on the production of natural pasture in Mt. Carmel (Ramat Hanadiv)-1989/90.

season, the only treatment showing a significant increase over the control was that of inoculation + P-fertilization. The decrease in the effect observed with the inoculation treatment in May (Fig. 3) is explained by damage caused by a selective gazelle grazing after the defending fence was left open.

At the peak of the 1990 growing season (April), dry matter yields were $2,150,2,730$, and 3,880 , and $1,580 \mathrm{~kg} / \mathrm{ha}$ in the inoculation, fertilization, inoculation + fertilization, and control treatments, respectively (i.e., an increase of $136 \%, 173 \%$, and $246 \%$ in response to the treatments). The respective rates of dry matter accumulation were $39,25,15$, and $15 \mathrm{~kg} / \mathrm{ha} / \mathrm{d}$.

Results of the third year (1991) were similar to those of the second (Fig. 4). In late April, dry matter yield in the control plots was $1,430 \mathrm{~kg} / \mathrm{ha}$, inoculation $-1,670 \mathrm{~kg} / \mathrm{ha}$, fertilization $-2,250$ $\mathrm{kg} / \mathrm{ha}$, and inoculation + fertilization $3,590-\mathrm{kg} / \mathrm{ha}(117 \%, 157 \%$ and $251 \%$ of the control, respectively).

The rates of dry matter accumulation from mid-March to late April 1991 were $52,32,24$, and $20 \mathrm{~kg} / \mathrm{ha} / \mathrm{d}$ for the combined treatment, fertilization, inoculation, and control plots, respectively.

In the greenhouse experiments (Fig. 5), the first and second harvests of the control treatment showed statistically lower yields than those of the other treatments. By contrast, in the third harvest, the inoculation and combined treatments resulted in significantly higher yields, as compared with the control and fertilization treat-

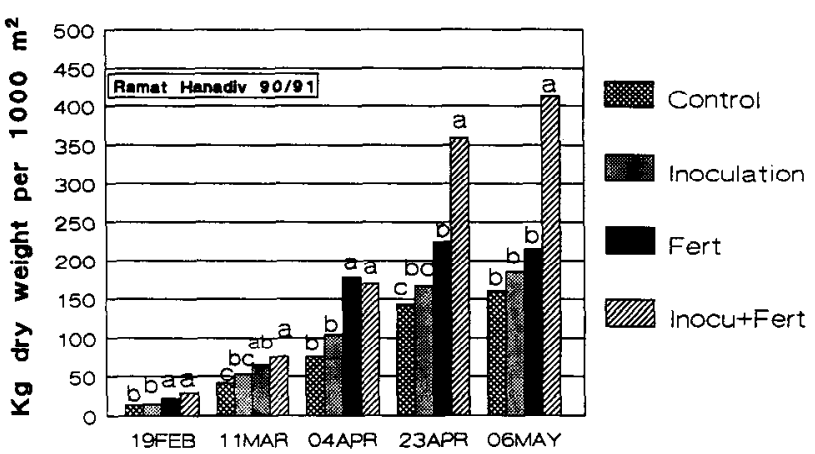

Harvest dates

Fig. 4. Effect of inoculation with Azospirillum brasilense Cd and phosphate fertilization on the production of natural pasture in Mt. Carmel (Ramat Hanadiv)-1990/91.

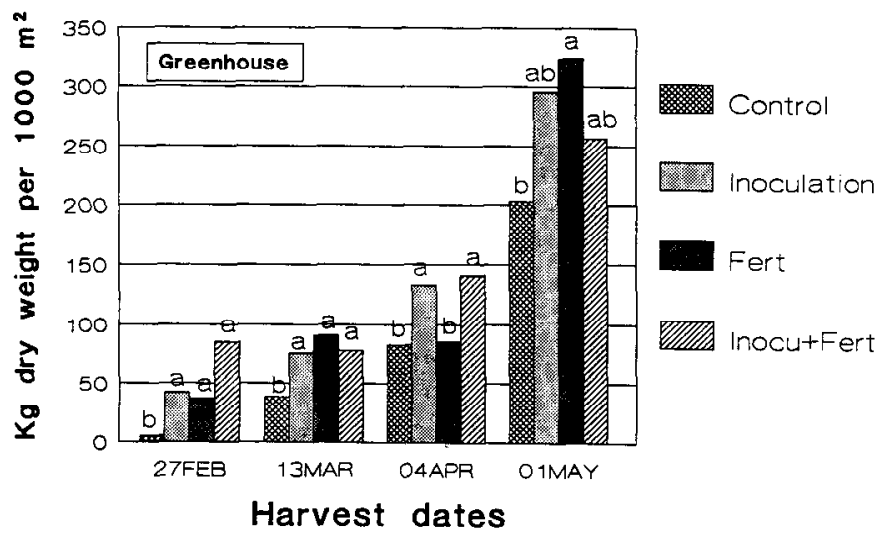

Fig. 5. Effect of inoculation with Azospirillum brasilense Cd and phosphate fertilization on the yield of herbaceous vegetation in pots (Greenhouse)

ments. However, just after the end of the growing season (beginning of May), only the fertilization treatment was statistically different from the control, with only slight differences for inoculation alone and fertilization + inoculation treatments.

\section{Discussion}

The findings reported in this paper indicate strongly that inoculation with Azospirillum brasilense bacteria has the potential of becoming an applicable range improvement technique under various ecological conditions. The effects of Azospirillum inoculation and phosphate fertilization on pasture yields varied from one experimental site to the next. In the semiarid ecosystem, response to inoculation with Azospirillum was very strong for both years. The accumulation rate of dry matter was 3.8 times higher than the control. At the peak of the growing season (end of April) the effect of inoculation was significantly higher than that of fertilization, while the yield with the combined treatment did not differ significantly from that of inoculation alone. In other words, inoculating the range with Azospirillum is a feasible alternative to expensive fertilization in semiarid habitats.

Bacterial inoculation + phosphate fertilization yielded $100 \mathrm{~kg}$ dry matter/ha (minimum biomass for grazing livestock) 4 to 5 weeks earlier than did the untreated plots in the northern Negev. This is economically significant because it allows the farmer to save on supplemental fodder used normally throughout the end of 
autumn and the beginning of winter when there is no pasture herbage on the range (Perevolotsky et al. 1991).

Unlike the experimental plots of the semiarid region, those in Ramat Hanadiv had been completely covered with a dense stand of perennial shrubs that were removed during the first season (September 1988). The cleared, newly exposed plots were, most certainly, lacking in seeds of herbaceous species, resulting in a low herbage yield the following season, and, consequently, no treatment effect. During the second and third experimental seasons, the rate of herbaceous pasture yield accumulation was clearly affected by inoculation or fertilization, but the highest significant effects were obtained with the combined treatment $(2.5-$ to 2.6 -fold increase in dry matter accumulation rate over the control), when compared with inoculation alone (1.2-fold) or with fertilization alone (1.6-fold).

In the Mediterranean terra rossa soil, the main factor limiting herbage production is phosphate, rather than nitrogen or water (Henkin et al. 1990). It is assumed that the inoculation + phosphate fertilization gave the highest production values due to combined effect of elevated soil phosphate levels and increased root surface area (due to Azospirillum), resulting in an increase in overall phosphate uptake by the plants (Okon 1985). Fertilization alone raised, most certainly, the phosphate level in the soil and affected growth, but less than the combination treatment. Similar results were obtained using inoculation alone at low phosphate levels.

Generally speaking, results similar to those observed in the field were obtained in the greenhouse. Treatments increased biomass production significantly as early as the first sampling date, indicating that inoculation promotes the growth rates of individual plants. In the greenhouse, peak biomass accumulation appeared later in the season as compared with the field, due, most certainly, to the abundant water supply in the former during the period of plant growth.

The study of pasture improvement using growth-promoting bacteria as inoculant is still nascent. There is not enough information on the biological effects of Azospirillum inoculation or on the adequacy of its application techniques. It is, therefore, too early to provide an economic analysis of this technique or to compare fertilization and inoculation efficiencies. Nevertheless, the use of Azospirillum inoculation appears to be much cheaper than fertilization based on a comparison of the cost of its application in agricultural crops such as corn, sorghum, and sunflower as compared with NP fertilization (Okon 1985). Whether the benefits suffice to justify inoculation of rangelands is not yet clear and requires further investigation. Nonetheless, inoculation has been shown to have no hazardous effects on the environment or the plants (Fages 1992), making it an ecologically sound alternative to fertilization.

\section{Literature Cited}

Baldani, V.L.D., J.I. Baldani, and J. Dobereiner. 1983. Effects of Azospirillum inoculation on root infection and nitrogen incorporation in wheat. Can. J. Microbiol. 29:924-929.

Barbieri, P., T. Zanelli, E. Galli, and G. Zanetti. 1986. Wheat inoculation with Azospirillum brasilense Sp6 and some mutants altered in nitrogen fixation and indole-3-acetic acid production. FEMS Microbiol. Lett. $36: 87-90$.

Fages, J. 1992. An industrial view of Azopirillum inoculants: production and application technology. Symbiosis 13:15-26.

Fallik, E., Y. Okon, E. Epstein, A. Goldman, and M. Fisher. 1989. Identification and quantification of IAA and IBA in Azospirillum brasilenseinoculated maize roots. Soil Biol. Biochem. 21:147-153.

Fallik, E., Y. Okon, and M. Fisher. 1988. Growth response of maize roots to Azospirillum inoculation: effect of soil organic matter content, number of rhizosphere bacteria and timing of inoculation. Soil Biol. Biochem. 20:45-49.

Freund, R.J., and Littell, R.C. 1980. SAS for linear models: a guide to the ANOVA and GLM procedure. SAS Institute, Cary, N.C.

Hegazi, N.A., M. Mahib, H.A. Amar, and E.S. Shokr. 1983. Response of maize to inoculation with Azospirilla and (or) straw amendment in Egypt. Can. J. Microbiol. 29:888-894.

Henkin, Z., I. Noy-Meir, U. Kafkafi, and M. Gutman. 1990. The influence of phosphate fertilizer application on natural pasture in Galilee: triannual summary. Hassade 71:283-287 (in Hebrew-English abstract).

Kaplan, M. 1989. The soils of Ramat Hanadiv-The southern Carmel. Res. Rep., (in Hebrew-English abstract).

Kapulnik, Y., J. Kigel, Y. Okon, I. Nur, and Y. Henis. 1981. Effect of Azospirillum inoculation on some growth parameters and $\mathrm{N}$-content of wheat, sorghum and panicum. Plant Soil 61:65-70.

Lin, W., Y. Okon, and R.W.F. Hardy. 1983. Enhanced mineral uptake by Zea mays and Sorghum bicolor roots inoculated with Azospirillum brasilense. Appl. Environ. Microbiol. 45:1775-1779.

Mertens, T., and D. Hess. 1984. Yield increases in Spring wheat (Triticum aestivum ) inoculated with Azospirillum lipoferum under greenhouse and field conditions of temperate regions. Plant Soil 82:87-99.

Noy-Meir, I., and Y. Harpaz. 1978. Agro-ecosystems in Israel. p. 143-167. In: M.J. Frissel (ed.), Cycling of mineral nutrients in agricultural ecosystems, Developments in Agricultural and Managed-Forest Ecology, 3. Elsevier, N.Y.

Okon, Y. 1985. Azospirillum as a potential inoculent for agriculture. Trends Biotechnol. 3:223-228.

Perevolotsy, A., N. Seligman, R. Yonatan, and S. Talker. 1991. Fertilizing semi-arid rangelands in the northern Negev-an ecological analysis. 4th Int. Rangeland Congr., Montpellier, France 22-25 April 1991.

Reynders, L., and K. Vlassak. 1982. Use of Azospirillum brasilense as biofertilizer in intensive wheat cropping. Plant Soil 66:217-223.

Sarig, S., A. Blum, and Y. Okon. 1988. Improvement of water status and yield of field grown grain sorghum (Sorghum bicolor) by inoculation with Azospirillum brasilense. J. Agr. Sci. 110:271 277.

Sumner, M.E. 1990. Crop responses to Azospirillum inoculation. p. 53-123. In: B.A. Stewart (ed.). Advances in soil science. Springer-Verlag, N.Y.

Umali-Garcia, M., D.H. Hubbell, M.H. Gaskins, and F.B. Dazzo. 1980. Association of Azospirillum with grass roots. Appl. Environ. Microbiol. 39:219-226

Wight, J.R., and A.L. Black. 1979. Range fertilization: plant response and water use. J. Range Manage. 32:345-349. 